\title{
AD/RHIC/RD-44
}

\section{RHIC PROJECT}

\author{
Brookhaven National Laboratory
}

\section{Outgassing Rate of Reemay Spunbonded Polyester and Dupont Double Aluminized Mylar}

\author{
R. J. Todd, D. Pate, K. M. Welch
}

September 1992 


\title{
OUTGASSING RATE OF REEMAY SPUNBONDED POLYESTER AND DUPONT DOUBLE ALUMINIZED MYLAR
}

\author{
R.J. Todd, D. Pate, K.M. Welch \\ Brookhaven National Laboratory
}

August 1992

\begin{abstract}
This paper presents the outgassing rates of two commercially available multi-layer insulation (MII) materials commonly used in cryogenic applications. Both Reemay Spunbonded Polyester and Dupont Double Aluminized Mylar (DAM) were studied for outgassing species and respective rates, and the total amount of outgassed material. Measurements were made using a Fixed Aperture Technique. A sample was pumped on through an aperture of known size with a turbomolecular pump. Pressure vs. time was plotted for both Reemay and $D A M$, as well as the baseline system, and data conveniently extrapolated to $\approx 1000 \mathrm{hrs}$. A quadrupole residual gas analyzer was used to measure the outgassing species.
\end{abstract}




\section{INTRODUCTION}

MLI is extensively used in the RHIC (Relativistic Heavy Ion Collider) cryostats. This insulating material comprises MLI blankets which are wrapped around the superconducting cold-mass and other surfaces within the cryostat. A cross section of a typical dipole cryostat and magnet is shown in Fig. 1.0. Twelve of these cryostats measure 480 meters in length.

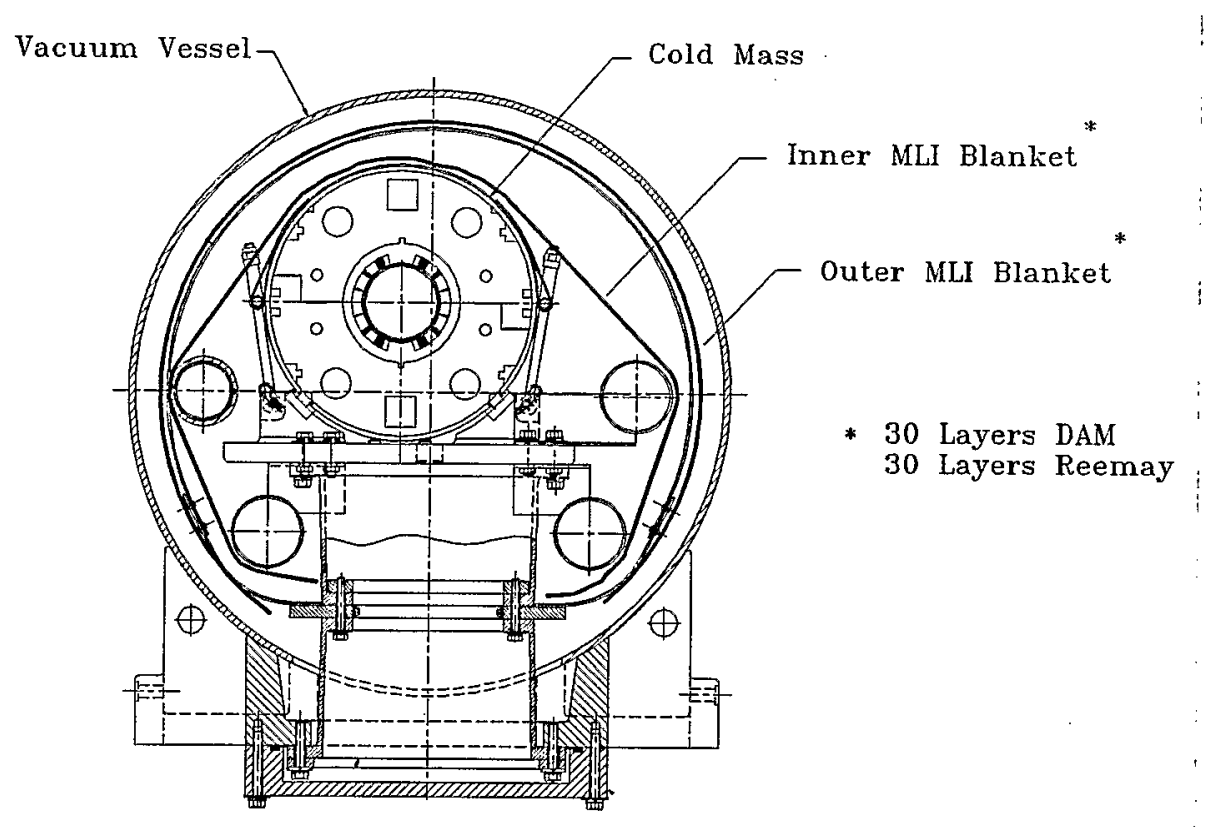

Figure 1.0 Cross Section of Dipole Magnet and Cryostat

$4 \times 10^{9}$ Due to the large amounts of MLI in each 480 meter cryostat, $\approx$ $\mathrm{Cm}^{2}$, its outgassing rate has an adverse effect on the pumpdown of the insulating vacuum as well as delaying effective leak checking of the cryostat. Outgassing rate information must be obtained so suitable rough pump systems can be configured to handle the estimated gas load.

\section{EXPERIMENTAL}

The test apparatus, represented in Fig. 2.0, consisted of a test chamber with an area of $1.92 \times 10^{3} \mathrm{~cm}^{2}$, into which the sample was installed. This chamber was pumped on through an orifice of diameter $0.612 \mathrm{~cm}$ by a turbomolecular pump with $\mathrm{S}_{\text {water }}=30 \mathrm{l} / \mathrm{s}$. The 
$0.612 \mathrm{~cm}$ orifice gave an effective pumping speed at the vessel of $3.36 \mathrm{l} / \mathrm{s}$ for water vapor. Two Varian UHV-24 Bayard-Albert Gauges, controlled by a Granville Phillips 271 controller were used, as well as an Inficon Quadrex 200 QRGA. The Reemay sample was $144.8 \mathrm{~cm}$ $\times 3,048 \mathrm{~cm}$, comprising a total surface area of $8.83 \times 10^{5} \mathrm{~cm}^{2}$. The DAM sample was $182.9 \mathrm{~cm} \times 3,048 \mathrm{~cm}$, with a total surface area of $1.115 \times 10^{6} \mathrm{~cm}^{2}$. Weights of each sample were 685.50 grams and 455.97 grams respectively. Each sample was loosely rolled and inserted into the test chamber.

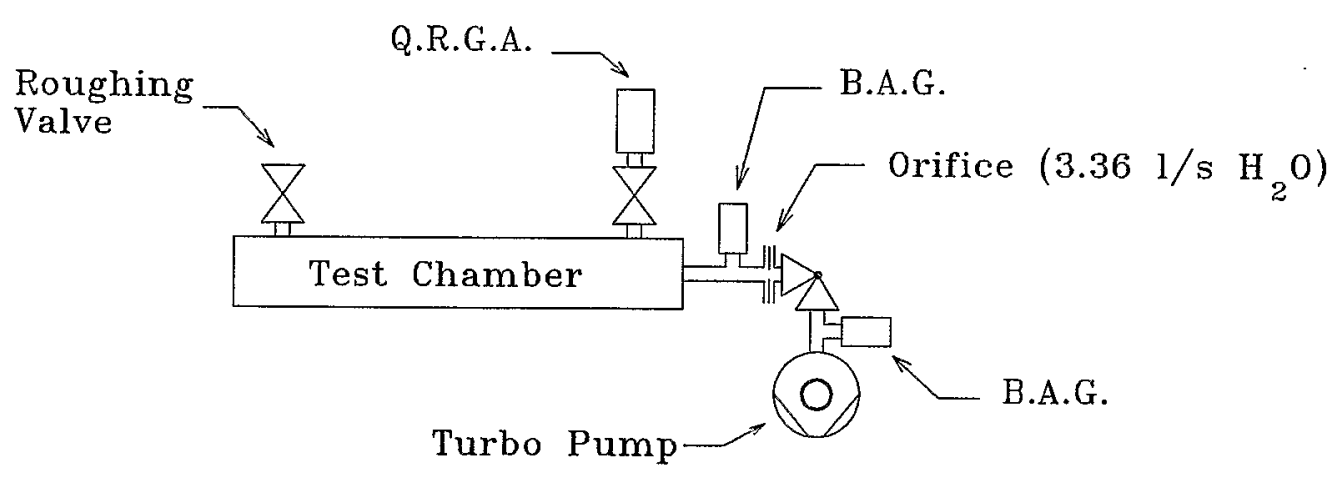

Figure 2.0 System Block Diagram

Baseline data of the system was taken for 24 hours prior to tests with MLI to establish system outgassing. The system was initially rough pumped through $V_{r}$ by a cryosorption pump to a pressure of 100 microns. At this time the Turbo pump was valved in running at $100 \%$ speed and $V_{\mathrm{r}}$ subsequently closed. The rate of pumpdown was recorded for 100 hours or more for each sample until a pressure decay slope could be accurately charted.

The basis for measuring the outgassing rate is as follows:

$$
Q(t)=P(t) \times S
$$

where $\mathbf{S}$ in our case is the effective speed at the vessel for water at $296^{\circ} \mathrm{K}$, and is a constant. A pumpdown curve was generated for pressure vs. time for each material. This plot is useful in that it reveals anomalies that may exist in the outgassing rate at lower pressures. Knowing the effective pumping speed, the pumpdown curve was converted to a graph of $q$ vs. $t$, where $q$ is the 
outgassing rate per unit area and $t$ is time in hours.

The total amount of outgassed material per unit Area $a_{\text {surface }}$ can be expressed by:

$$
\int Q(t) d t=S \int P(t) d t
$$

These data are readily obtained by graphically integrating the plots of $q \mathrm{vs}$ time shown in Figs. 3.1 and 3.2 .

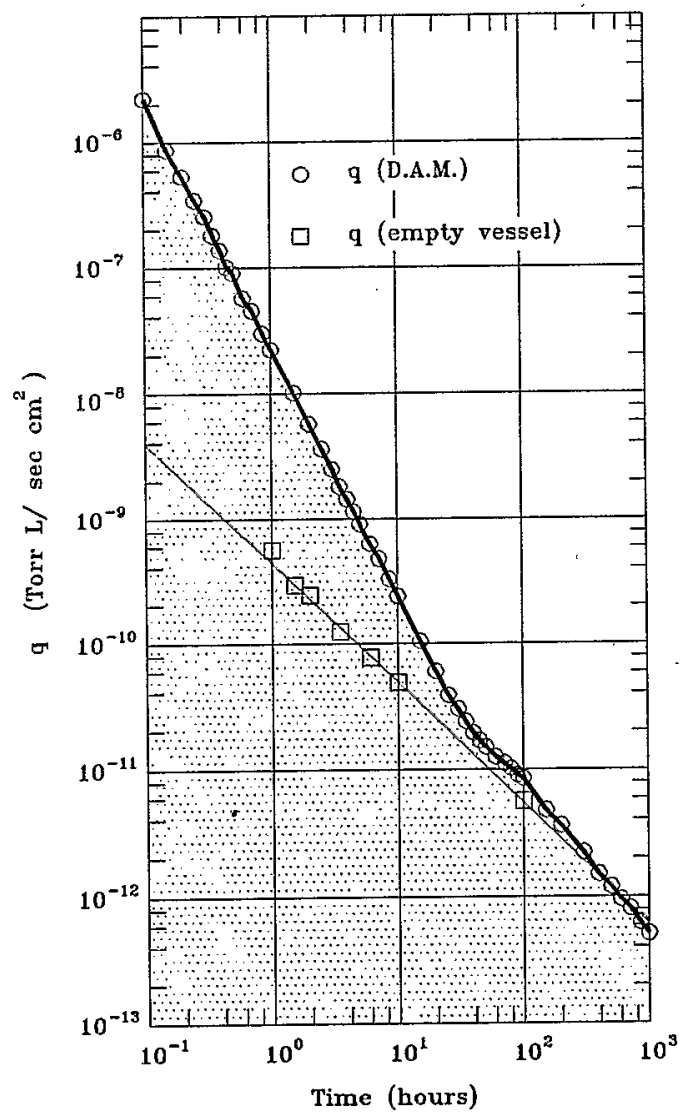

Figure 3.1 DAM Outgassing Rate va. Time

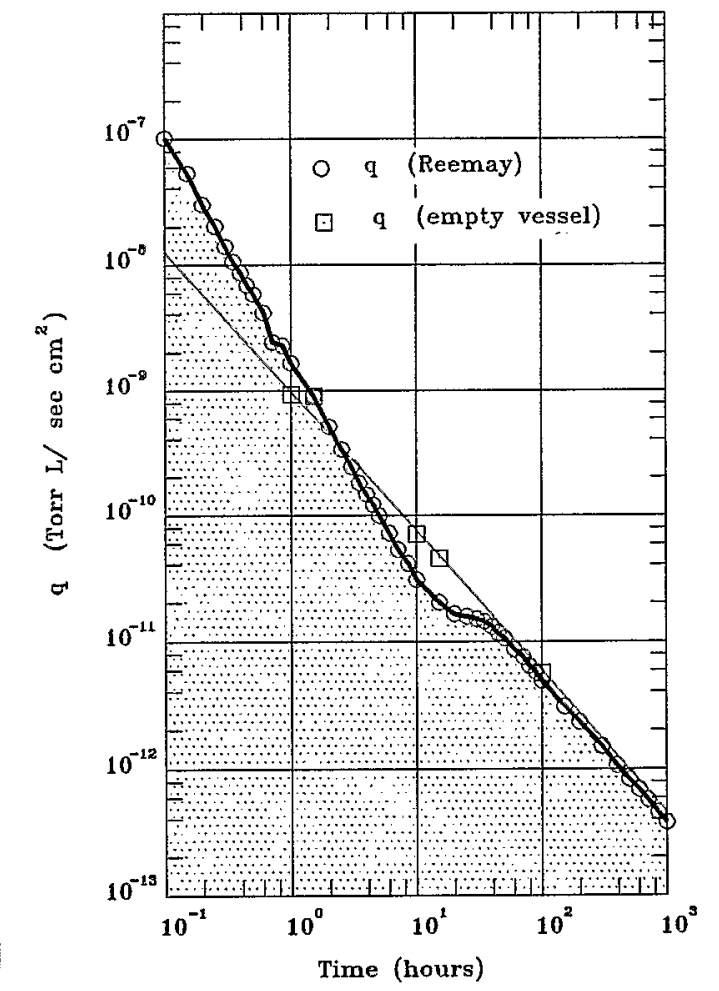

Figure 3.2 Reemay Outgassing Rate vs. Time 


\section{RESULTS}

The outgassing rates and spectrum for both DAM and Reemay are shown in Figures 3 through 6. Figures 5 and 6 show that the major constituent of the outgassing is water vapor. This is true for both the DAM and Reemay material. It can be seen in both graphs that the baseline outgassing rate did not significantly impact on the total outgassing rate since the area of the samples were $\approx 500$ times that of the test chamber. The total water contribution by the test chamber was $\approx 6.45 \times 10^{-3}$ grams, or < $1 \%$ of the samples.

Two things are readily apparent from the graphs. The first being the knee in the outgassing slope of the Reemay. This knee occurs after 10 hours of outgassing where the slope goes from -1.77 to -0.33 . This slope remains for roughly $40 \mathrm{hrs}$ and then falls off to a new slope of -1.1 . This change in slope occurs because the outgassing becomes "diffusion limited". Once most of the surface outgassing is complete, we speculate an "inter-layer" diffusion process occurs due to the long and arduous path the water vapor must take in being liberated. The initial surface outgassing changes rapidly with time (dQ/dt), while the "inter-layer" diffusion process remains more constant. After $\approx 30$ hours, dQ/dt decreases to a value roughly $60 \%$ of the original surface outgassing rate. This "knee" is not representative of MLI, since Reemay is used as a spacer in one layer thicknesses. This effect is not as pronounced in the DAM where only a slight change in the slope is observed.

The second observation worth noting is the higher outgassing rate of the DAM. The initial $q$ of the DAM is $\approx 23$ times that of the Reemay. After one hour $\mathrm{q}_{\mathrm{DAM}}=2.26 \times 10^{-6} \mathrm{Torr}-\mathrm{I} / \mathrm{sec} \mathrm{cm}^{2}$, compared to $1.00 \times 10^{-7}$ Torr-L/sec $\mathrm{cm}^{2}$ for the Reemay.

Another major observation is the spectrum of the Reemay material. The baseline spectrum (Fig. 3.3) shows only modest amounts of $\mathrm{CO}_{2}$ at a pressure of $1.6 \times 10^{-6}$ Torr. With the Reemay inserted, the spectrum shows appreciable amounts of hydrocarbons at a total pressure of $3.5 \times 10^{-6}$ Torr (Fig. 3.3.2). These hydrocarbon peaks occur at amu $39,41,43$, and 44 , with partial pressures of $5.2 \times 10^{-8}, 9.1 \times 10^{-8}, 1 \times 10^{-7}$, and $9.0 \times 10^{-8}$ Torr respectively. Peaks of $\approx$ $4 \times 10^{-8}$ Torr also occur at 55 and 57 . These Hydrocarbons are likely a by-product of the Reemay manufacturing process. This may be noteworthy to those designing superconducting magnets who wish to pump Helium leaks with molecular sieve material. This material, bonded to the cold-mass, may become plugged due to the hydrocarbons and water present in the insulating vacuum. 'The DAM spectrum (Fig. 3.4) shows no appreciable amounts of outgassed hydrocarbon material.

The total amount of outgassed water is of particular importance. This impacts on the mechanical pumps being used to evacuate the RHIC cryostats. Table 3.5 shows the total amount of water contained per $\mathrm{cm}^{2}$ of material, as well as the total for a 480 meter cryostat. 


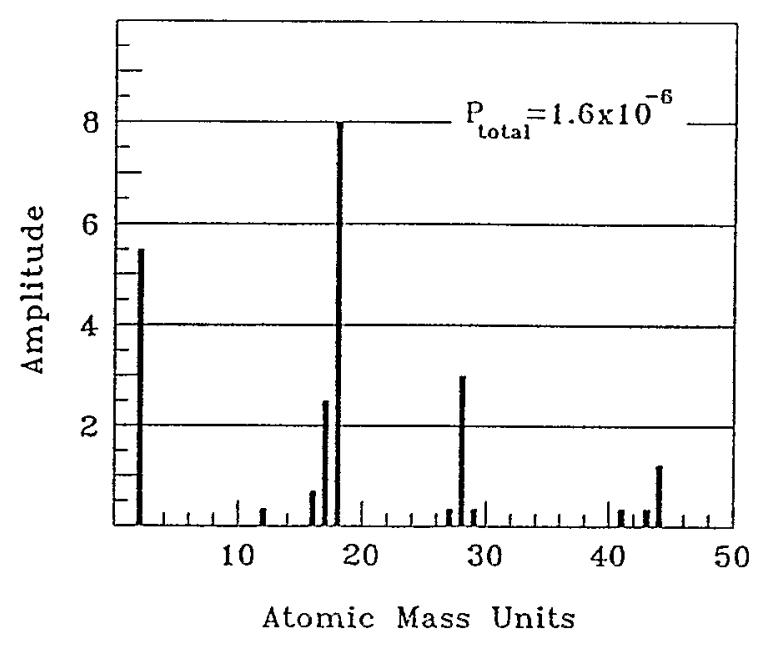

Figure 3.3 Empty Vessel Spectrum @18 hours

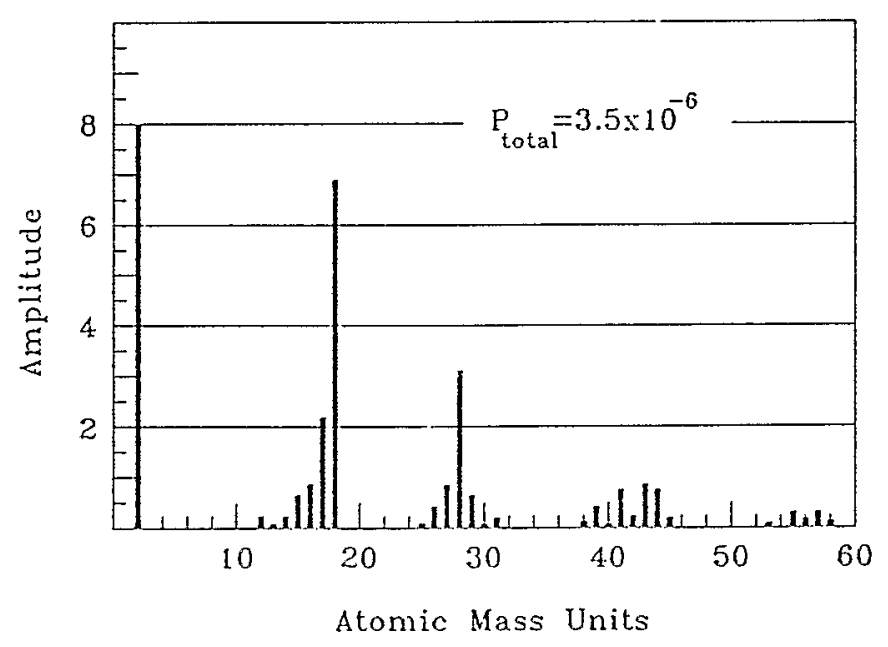

Figure 3.3.2 Spectrum @ 56 Hours (Reemay)

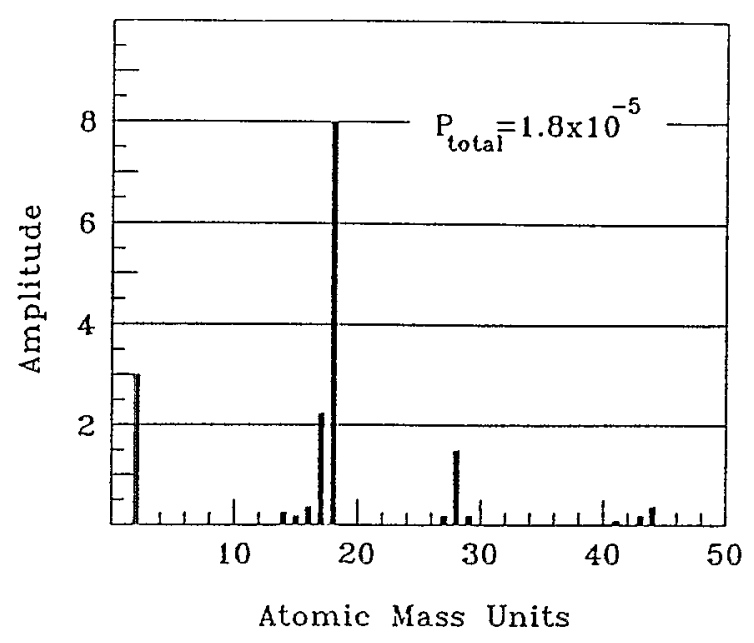

Figure 3.3.1 Spectrum @ 7.5 Hours (Reemay)

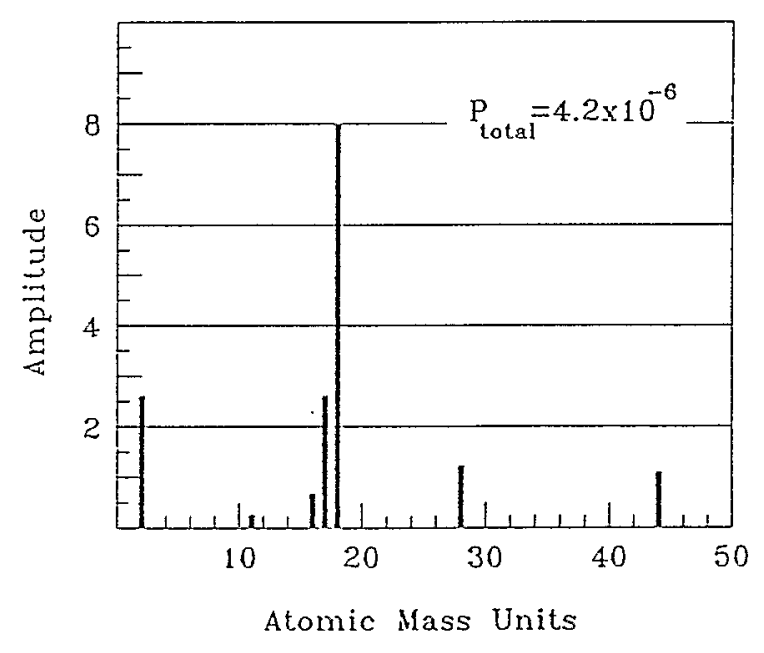

Figure 3.4 Spectrum (9) 75 Hours (D.A.M.) 


\begin{tabular}{|c|c|c|}
\hline \multirow[t]{2}{*}{ MATERIAL } & \multicolumn{2}{|c|}{ TOTAL OUTGASSED WATER } \\
\hline & $\begin{array}{c}\text { per unit } \\
\text { area }\end{array}$ & $\begin{array}{c}\text { per } 480 \text { meter } \\
\text { cryostat }\end{array}$ \\
\hline $\begin{array}{c}\text { Reemay } \\
\text { spunbonded polyester }\end{array}$ & $9.78 \times 10^{-8} \mathrm{~g} / \mathrm{cm}^{2}$ & $2.27 \times 10^{2}$ grams \\
\hline $\begin{array}{c}\text { double aluminized } \\
\text { mylar }\end{array}$ & $1.63 \times 10^{-6} \mathrm{~g} / \mathrm{cm}^{2}$ & $3.15 \times 10^{3}$ grams \\
\hline $\begin{array}{l}\text { ambient air } \\
\text { c } 70 \% \text { rel. humidity }\end{array}$ & $\mathrm{PP} \approx 10$ Torr & $1.2 \times 10^{3}$ grams \\
\hline $\begin{array}{c}\text { steel vacuum } \\
\text { vessel }\end{array}$ & $3.38 \times 10^{-6} \mathrm{~g} / \mathrm{cm}^{2}$ & $\approx 5$ grams \\
\hline
\end{tabular}

Table 3.5 Total Water Accumulations

The DAM contains $\approx 17$ times the amount of water per unit area than the Reemay material. The total amount of water contained in the $D A M$ and Reemay is $\approx 3.38$ liters. The water contained in the air within the insulating vacuum prior to roughing is approximately 1.2 liters, while the amount on the vessel walls is negligible. The total water in each 480 meter cryostat prior to roughing is 4.58 liters. This will be shared equally by four pumps, each having to handle 1.15 liters. A cold trap of adequate size will be used to handle this load. This will aid in leak checking the cryostats through the rough pumps by reducing the partial pressure of water at the leak detector. It will also reduce contamination of the rough pump oil.

The results of the test are in agreement with previous work done with MLI. ${ }^{2}$ Published work on the outgassing rate of DAM reported totals of $1.1 \times 10^{-6} \mathrm{~g} / \mathrm{cm}^{2}$ surf, area, and $2.6 \times 10^{-3} \mathrm{~g} / \mathrm{g}_{\text {sauple mass }}$. These results, compared to $1.63 \times 10^{-6} \mathrm{~g} / \mathrm{cm}^{2}$, and $3.99 \times 10^{-3} \mathrm{~g} / \mathrm{g}$, are $\approx 50 \%$ lower. This is attributed to the room humidity at the time the sample was installed in the test chamber.

\section{CONCLUSIONS}

The outgassing rates of DAM and Reemay have been established, and the amount of water from each determined.It is evident that the DAM carries much more bulk water than the Reemay spacer material. A total of 4.48 liters of water are contained in each 
RHIC Cryostat. With this information, properly sized cold traps can be installed on the rough pumps.

The way in which the Reemay outgasses is also of particular interest. Once bulk outgassing is complete, a diffusion limited process takes place. This effect may show itself in application since the RHIC insulating blankets comprise 30 layers at a length of 10 meters.

Hydrocarbons were noted to outgass from the Reemay material. This release could have irreversible plugging affects on sieve material in proximity to the MLI.

1.Welch, K.M., CAPTURE PUMPING TECHNOLOGY (Pergamon Press Inc., New York, 1991), p.280.

2. Glassford, A.P.M., Liu, C.K., "Outgassing Rate of Multilayer Insulation",J. Vac. Sci. Technol.,17(3),696(1980). 


\section{OUTGASSING RATE OF REEMAY SPUNBONDED POLYESTER AND DUPONT DOUBLE ALUMINIZED MYLAR \\ ADDENDUM TO THE TOTAL OUTGASSED WATER OF REEMAY AND DAM

\author{
R. Todd, D. Pate, K.M. Welch \\ Brookhaven National Laboratory
}

September 1992

When generating the graphs of outgassing rate vs. time for the Reemay and DAM, data was collected after one hour of pumping and extrapolated to a lower and upper limit of $10^{-1}$ and $10^{3}$ hour respectively.

In calculating the total outgassed water of the MLI, the graphs of outgassing rate vs. time (Fig. 3.1, 3.2) were graphically integrated over the interval $10^{-1}$ to $10^{3}$ hours. These total accumulations are given in Table 3.5. However, significant outgassing occurs prior to $10^{-1}$ hour. This additional accumulation was not included in the integration. The graphs have been subsequently integrated over the interval $10^{-2}$ to $10^{3}$ and total accumulations adjusted accordingly. The updated data are given in the following table. The estimated total for a 480 meter cryostat is $\approx 34.1 \mathrm{~kg}$.

\begin{tabular}{|c|c|c|}
\hline \multirow[t]{2}{*}{ MATERIAL } & \multicolumn{2}{|c|}{ TOTAL OUTGASSED WATER } \\
\hline & $\begin{array}{c}\text { per unit } \\
\text { area }\end{array}$ & $\begin{array}{c}\text { per } 480 \text { meter } \\
\text { cryostat }\end{array}$ \\
\hline $\begin{array}{c}\text { Reemay } \\
\text { spunbonded polyester }\end{array}$ & $4.00 \times 10^{-6} \mathrm{~g} / \mathrm{cm}^{2}$ & $9.27 \times 10^{3}$ grams \\
\hline $\begin{array}{c}\text { double aluminized } \\
\text { mylar }\end{array}$ & $1.23 \times 10^{-5} \mathrm{~g} / \mathrm{cm}^{2}$ & $2.36 \times 10^{4}$ grams \\
\hline $\begin{array}{l}\text { ambient air } \\
\text { e } 70 \% \text { rel. humidity }\end{array}$ & $\mathrm{PP} \approx 10$ Torr & $1.2 \times 10^{3}$ grams \\
\hline $\begin{array}{c}\text { steel vacuum } \\
\text { vessel }\end{array}$ & $3.38 \times 10^{-6} \mathrm{~g} / \mathrm{cm}^{2}$ & $\approx 5$ grams \\
\hline
\end{tabular}

Table 3.5 Total Water Accumulations 